\title{
COMPUTER LITERACY ENHANCEMENT IN THE TEACHING HOSPITAL OLOMOUC. PART I: PROJECT MANAGEMENT TECHNIQUES. SHORT COMMUNICATION
}

\author{
Drahomír Sedlár̆a , Jarmila Potomkováb, Jarmila Řehořováa, Pavel Sečkárán, Věra Sukopováa \\ a Teaching Hospital Olomouc, I. P. Pavlova 6, 77520 Olomouc, Czech Republic, e-mail:drahomirsedlar@fnol.cz \\ ${ }^{b}$ Palacký University Faculty of Medicine, Hněvotínská 3, 77503 Olomouc, Czech Republic
}

Received: June 15, 2003

Key words: Information technology skills / Long-life education / Healthcare / Project management/ Brainstorming/ SWOT analysis

Information explosion and globalization make great demands on keeping pace with the new trends in the healthcare sector. The contemporary level of computer and information literacy among most health care professionals in the Teaching Hospital Olomouc (Czech Republic) is not satisfactory for efficient exploitation of modern information technology in diagnostics, therapy and nursing. The present contribution describes the application of two basic problem solving techniques (brainstorming, SWOT analysis) to develop a project aimed at information literacy enhancement.

\section{BACKGROUND OF THE PROJECT}

In the planning stage of the project information retrieval was performed to estimate the contemporary trends in enhancing computer and information literacy of healthcare professionals worldwide. In the last decade of the 20th century health care services in the developed countries of the world were undergoing dynamic and core changes. In the context of building the information society of the $21^{\text {st }}$ century implementation and efficient use of information technology are coming to the forefront. A dramatic increase in the amount of available clinical information resources is a tool for improving diagnosis and therapy, but only when "best evidence" is brought to the point of decision-making. The Internet is a powerful engine contributing to this transformation offering the environment for electronic patient records, practice guidelines, user-friendly health portals and wireless communication. The new paradigm of health care delivery consists of a multidisciplinary team of clinician and non-clinician providers (including information professionals) and is oriented on optimization of patient outcomes. The team work is a major prerequisite for continuous quality improvement following a sustainable upward spiral. The continuous quality improvement is closely related to such issues as cost containment, higher level of patient and provider satisfaction, better health status and quality of life of the population. The data obtained from the world biomedical literature confirm that in most health care settings it is especially common to underestimate the time required for training personnel in the use of information tools. It has also been shown that the organizations that pay a permanent attention to long-life education of their employees ("learning organizations") are increasing their readiness to change, because a higher level of readiness can reduce innovation risk and bring about a more successful IT outcome. ${ }^{1-4}$

\section{TEAM BUILDING}

A multidisciplinary team was established with the aim to assess the contemporary level of computer literacy among healthcare professionals in the Teaching Hospital Olomouc (Czech Republic) and propose a modular training course in information technology skills suited for different categories of the employees. The team was composed of specialists in the information and communication technology, healthcare management, nursing and medical education, statistics and librarianship. Another aspect of the team building was to select suitable individuals "to cast in" specific roles during implementation of the project (i.e. co-ordinators, analysts, statisticians, implementers, resource investigators, team workers). ${ }^{5}$

\section{PROJECT DEVELOPMENT}

The process of project development was based on two basic problem solving techniques, ${ }^{6}$ namely brainstorming and SWOT analysis. 


\section{Technique I: Brainstorming}

Brainstorming belongs to methods for developing creative solutions to problems. There are some generally adopted rules how to brainstorm: participants of a session should focus on a problem, offer plenty of [unusual] solutions, push the ideas as far as possible, not criticize or evaluate any ideas during the session, analyse the results, and finally select the best option. A session leader plays an important role being responsible for the control of the session, definition of the problem to be solved, maintenance of enthusiastic and non-critical atmosphere, adequate participation of all the members, orientation on practical solutions, and last but not least keeping records of the session. ${ }^{7}$

Brainstorming can be done either in groups or individually. Because of the lack of experience with the technique itself, a mixture of both the types was used at the initial stage of the project, starting with individual brainstorming which produced a broad range of ideas, though sometimes "shallow" ones. On the other hand, it gave opportunities to creative but quiet people without being limited by time, and dominated by other group members. The individual brainstorming was then followed up by the group session which formulated practical goals of the future project:

1. Assess the contemporary state of computer literacy among healthcare professionals in the Teaching Hospital Olomouc.

2. Define standard levels of information technology (IT) knowledge for different categories of healthcare professionals in view of clinical, nursing and biomedical information.

3. Elaborate methods how to achieve the proposed standards and develop a modular training course (curricula). ${ }^{8}$

4. Verify the efficiency of the proposed methods and practical outcomes by means of staff surveys.

5. Improve nurses capabilities to routinely use elctronic nursing documentation.

\section{Technique II: SWOT analysis}

SWOT stands for Strengths - Weaknesses - Opportunities - Threats. It aims to identify the strengths and weaknesses of an organization, and the opportunities and threats in the environment. The advantage of SWOT analysis is its capability to connect internal factors to formulate new strategies..$^{9,10}$

The manager of the project under consideration decided to start SWOT analysis with drawing attention to the aspects that represented the weaknesses. It is a well-known-fact that clearly specified weaknesses can be converted into challenges and serve as incentives. The list of the weaknesses contained the issues we thought we could improve, overcome, and/or achieve in the Teaching Hospital Olomouc:
- Imbalance in information technology (IT) skills and competencies among different categories of healthcare professionals.

- Absence of a structured system of training courses for end-users with different levels of IT knowledge.

- Volunteeriness in IT knowledge enhancement among hospital staff.

- Computer phobia typical for older generations.

- Insufficient exploitation of currently available Internet and Intranet tools and resources due to insufficient training of end-users.

The next step of SWOT analysis was focused on discussing the opportunities which could be exploited in favour of our intentions, in particular:

- Possibility to submit a grant proposal to the Czech Grant Agency IGA supporting biomedical research to get 2-year-funding.

- Access to technology-driven medical and healthcare information services provided by the joint learning resource centre of the Teaching Hospital and Palacký University Faculty of Medicine in Olomouc.

- Nationwide policy supporting implementation of the National Information System in hospitals and healthcare settings.

- Close vicinity of the Palacký University Faculty of Medicine with its educational capacity and the will to share knowledge and experience.

- Previous cooperation with the Institute for Postgraduate Medical Education (Prague, Czech R.) offering a modular training programme aimed at computer literacy improvement in medicine and healthcare since $2000 .{ }^{11}$

Surprisingly, the team produced a rich list of strengths that were considered powerful prerequisites for successful project implementation, e.g.

- Experienced and high-qualified team members.

- Qualifications of some team members to develop and implement training courses in biomedical information retrieval.

- Enthusiasm of facilitators to educate and interest in training among the hospital staff.

- Support from the hospital top management.

- Previous experience in national and international projects dealing with application of information technology in medicine and healthcare. ${ }^{12}$

It was fairly difficult to envisage threats that could hamper the project implementation. Finally, most of the team members agreed that they were afraid of insufficient funding, unexpected Internet and Intranet services failures, excessive workload, fatigue and low motivation of the hospital staff which would discourage them from participation in training courses. 


\section{EXPECTED OUTCOMES OF THE PROJECT}

- Knowledge standards in IT will be proposed for different categories of the health professionals in the Teaching Hospital Olomouc.

- Better readiness of the hospital staff to IT innovation will decrease the level of risk accompanying the implementation of the clinical information system in all departments and clinics.

- A modular training programme in information literacy (curricula) will be offered for long-life education of all categories of the personnel, including administrative staff.

\section{CONCLUSIONS}

The proposed project is based on 10-year experience in the developed countries witnessing dramatic socioeconomic changes in the society and institutions including healthcare settings that have adopted the theory of "learning organizations" and realized their responsibility for long-life education of their personnel. ${ }^{13}$ The above changes are partly due to the implementation of modern information and communication technology. This process is particularly challenging in the healthcare industry where IT is putting heavy demands on skills and competences of health professionals of all categories. Consequently, it is inevitable to develop long-life educational schemes to support the improvement of their

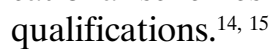

\section{ACKNOWLEDGEMENT}

The project is supported by the Grant Agency IGA (grant NO/7266-2).

\section{REFERENCES}

1. Berwick DJ. (1989) Continuous improvement as an ideal in health care. N Engl J Med 320, 53-56.

2. Herzlinger R. Market-driven health care. Reading, (MA): Perseus Books, 1997.

3. Haugh R. (1999) The new consumer. Hosp Health Netw 12, 30-36.

4. Kohn LT, Corrigan JM, Donaldson MS. To err is human: Building a safer health system. Washington (DC): National Academy Press, 1999.

5. Posner K, Applegart M. The project management pocketbook. [No date] [Online] [Access 2003 January]. Available from http:// www.pocketbook.co.uk/freeextracts/project_management_pocket book.pdf.

6. Mind tools - problem solving and analytical techniques. 1998 [Online] [Access 2001 December]. Available from http://www.psy www. com/mtsite/page 2.html.

7. El Ansari W, Russell J, Spence W, Ryder E, Chambers C. (2003) New skills for a new age: leading the introduction of public health concepts in healthcare curricula. Pub Health 2, 77-87.

8. Durisin P. Information literacy programs: successes and challenges. New York: Haworth Press, 2002.

9. Casebeer A. (1993) Application of SWOT analysis. Br J Hospital Med 6, 430-431.

10. Dyson RG. (2003) Strategic development and SWOT analysis at the University of York. Eur J Operat Res. In press. Corrected proof available online 1 April 2003.doi:10.1016/S0377-2217(03)00062-6.

11. Potomková J, Pessrová H, Bouzková H, Lesenková ES, Musil J, Komenda S. A new approach to continuing education for health sciences librarianship in the Czech Republic. In: Jakobsson A, van Loo J, editors. Abstracts. $8^{\text {th }}$ International Congress on Medical Librarianship, London, UK, 2-5 July 2000, p. 6.

12. Lesenková E, Potomková J. Clinical practice review. Good practice methods, approaches, information retrieval, quality assessment. In: CEE Regional LRC Dissemination Conference. Zadar, Croatia, 2002. American International Health Alliance, 2002, p. C40-C49.

13. Chawla S, Renech J. Learning organizations: Developing cultures for tomorrow's workplace. Portland (OR) Productivity Press, 1995.

14. Snyder-Halpern R. (2001) Indicators of organizational readiness for clinical information technology systems innovation: a Delphi study. Intnl J Med Informatics 63, 179-204.

15. Tierney WM. (2001) Improving clinical decisions and outcomes with information: a review. Intnl J Med Informatics 62, 1-9. 